\title{
Incidence and Predictors of Mortality among Children on Anti-Retroviral Therapy in Public Health Facilities of Arba Minch Town, Gamo Gofa Zone, Southern Ethiopia; Retrospective Cohort Study
}

Negussie Boti Sidamo ${ }^{1^{*}}$, Mesfin Kote Debere ${ }^{2}$, Bilcha oumer Enderis ${ }^{3}$ and Direslgne Misker Abyu ${ }^{2}$

${ }^{1}$ Department of Midwifery, College of Medicine and Health Sciences, Arba Minch University, Arba Minch, Ethiopia

${ }^{2}$ Department of Public Health, College of Medicine and Health Sciences, Arba Minch University, Arba Minch, Ethiopia

${ }^{3}$ Department of Midwifery, Arba Minch College of Health science, Arba Minch, Ethiopia

*Corresponding author: Negussie Boti Sidamo, Department of Midwifery, College of Medicine and Health Sciences, Arba Minch University, Arba Minch, Ethiopia, Tel: +251920997752; E-mail: kahlidboti@gmail.com

Received date: July 04, 2017; Accepted date: August 10, 2017; Published date: August 20, 2017

Copyright: $\odot 2017$ Sidamo NB, et al. This is an open-access article distributed under the terms of the Creative Commons Attribution License, which permits unrestricted use, distribution, and reproduction in any medium, provided the original author and source are credited.

\begin{abstract}
Background: Evidence shows that earlier access to Anti-retroviral Therapy helps to increase survival of children by delaying the progression to AIDS. However its long-term effect on mortality has remained unanswered in Ethiopia especially in the study area.
\end{abstract}

Objective: To assess incidence and predictors of mortality among Children on Anti-retroviral Therapy in Public Health Facilities of Arba-Minch Town, Gamo Gofa zone, Southern, Ethiopia.

Methods: Institution based retrospective cohort study was employed among $421 \mathrm{HIV}$-positive children enrolled on anti-retroviral therapy from January $1^{\text {st }} 2009$ to December $30^{\text {th }}$ 2016. The data on relevant variables was collected from patients' medical cards and electronic database by trained data collectors. Data was entered and cleaned by Epi Info version 7 and analyzed by STATA version 11. Life table was used to estimate the cumulative survival of children and Kaplan Meier survival curve together with log rank test was used to compare survival between different categories of covariates. Cox proportional-hazard regression model was used to identify independent predictors of mortality.

Result: Overall, $15.4 \%$ of children ( $n=65$ ) died over a follow-up period of 21,175 person-months of observation. The mortality rate of this cohort was 3.07 deaths per 1000 person-months. The cumulative probability of survival after $96^{\text {th }}$ month of treatment was $73.9 \%(95 \% \mathrm{Cl}=63.2-81.9)$. During the multivariate analysis of baseline variables, we observed that the delayed and regressed developmental milestone (AHR=4.42, 95\% Cl=1.99-9.75), (AHR=6, $95 \% \mathrm{Cl}=2.68-13.45)$, opportunistic infection at baseline (AHR=1.93, 95\% Cl=1.03-3.64), tuberculosis co-infection at base line $(A H R=2.28,95 \% C l=1.23-4.22)$, low hemoglobin level $(A H R=3.32,95 \% C l=1.83-6.04)$, absolute $C D 4$ below threshold $(\mathrm{AHR}=2.08,95 \% \mathrm{Cl}=1.15-3.77)$, fair and poor adherence to ART were $(\mathrm{AHR}=2.17,95 \%$ $\mathrm{Cl}=1.12-4.79),(\mathrm{AHR}=2.05,95 \% \mathrm{Cl}=1.02-4.13)$, isoniazid preventive therapy $(\mathrm{AHR}=0.38,95 \% \mathrm{Cl}=0.22-0.68)$ and Co-trimoxazole preventive therapy $(\mathrm{AHR}=0.26,95 \% \mathrm{Cl}=0.15-0.46)$ were independent predictors of mortality.

Conclusions: Mortality was high especially during the first sixth months following anti-retroviral therapy initiation. Therefore, higher priority should be given to HIV-infected children with tuberculosis co-infection further intervention like isoniazid preventive therapy and co-trimoxazole preventive therapy as well close follow should be given to all children after start of anti-retroviral therapy.

Keywords: Incidence; Children; Anti-retroviral Therapy; Mortality; Cox proportional hazard; Ethiopia

\section{Introduction}

HIV/AIDS remains one of the world's most significant public health challenges, particularly in low- and middle-income countries [1]. Children are the most valuable group continues affect by HIV and a major contributing to childhood morbidity, mortality and the commonest reason for paediatric hospital admission [2].

The most common first line drug regimen combinations given for HIV-infected children usually consists 2NRTIs+1NNRTI [2]. The drugs do not kill or cure the virus, but decrease the amount of virus in your bloodstream. However, when taken in combination they can prevent the growth of the virus and stop the progression of HIV disease. Adherence to ARVs is very important for treatment to work. The viral load test is used to see if ARV drugs are working. Current New guidelines recommended that everyone who is infected with HIV should start ARV therapy [2,3].

According to seventh stocktaking report that among total 1.8 million children living with HIV an estimated 1,10,000 children died of AIDS-related illnesses and 290 children died of AIDS-related illnesses every day. Nearly 90\% live in Sub-Saharan Africa in 2016 [4]. In Ethiopia it is estimated of 109133 children living with HIV, approximately 5760 AIDS related deaths each year in 2016 [5]. 
Citation: Sidamo NB, Debere MK, Enderis B, Abyu DM (2017) Incidence and Predictors of Mortality among Children on Anti-Retroviral Therapy in Public Health Facilities of Arba Minch Town, Gamo Gofa Zone, Southern Ethiopia; Retrospective Cohort Study. Clinics Mother Child Health 14: 267. doi:10.4172/2090-7214.1000267

Page 2 of 11

Evidence show that earlier access to ART shows that it help to increase survival of children by delaying the progression to AIDS $[6,7]$. It was estimated that earlier access to ART could have prevented $25 \%$ of HIV related death $[8,9]$. However, access to ART for children was only $12 \%$ among children under 15 years of age [1].

In Ethiopia, the HIV epidemic has remained a major public health problem, largely affecting children [10]. In Ethiopia, the fee based and universal free access antiretroviral (ARV) treatment was started in $2002 / 3$ and 2004/5 respectively [10]. Ethiopia has been engaged in the scale-up of ART access to the level of health center starting since 2006 [11]. The number of sites providing the ART service had increased from 3 to over 1000 including both public and private facilities and people started on treatment increased from 24,000 to 308,000 from 2006 to 2016 [10].

Mortality under ART in Africa remains high ranging from $7.5 \%$ to $15 \%$ [12-15]. Ethiopia ranging from $4.3 \%$ to $10.4 \%$ during the first six months following ART initiation [16-18]. The high Mortality rates of HIV-infected children under treatment in Africa are likely to depend not only on the care delivered by ART programs, but more fundamentally related to low CD4 count, WHO clinical stage, opportunistic infection and anemia [7,19,20].

In addition, the durability of the treatment response and its longterm effect on mortality remained unanswered $[16,21]$. Consequently, in resource limited settings like Ethiopia, there is a pressing need for research to further refine HIV treatment strategies among the children in order to have better survival of children after initiation of ART and in order to develop appropriate interventions to achieve the desired outcome of ART program as well to avoid unclear conclusions on the cause of mortality associated with children after starting ART. Therefore, the aim of this study was assessing incidence and identify predictors that affect the mortality of HIV positive children after initiation of ART in Public Health Facilities of Arba-Minch Town, Gamo-Gofa zone, Southern Ethiopia.

\section{Methods}

\section{Study area and period}

This study was conducted in Arba Minch town from March 20thApril 10th, 2017. Arba-Minch town was located about $505 \mathrm{~km}$ south west from Addis Ababa, about $275 \mathrm{~km}$ from Hawassa, the capital of the SNNPR region. Arba Minch town has one General hospital and one public health center, which provide ART service. Arba Minch hospital was among the first few public hospitals to start ART in Ethiopia in August 2003 and Arba Minch Health Center also start ART care by the end of 2007 [11]. According to Gamo Gofa zone health department report the Arba Minch hospital and Arba Minch health center provides HIV/AIDS interventions, including free diagnosis, treatment and monitoring. There are multidisciplinary professional's team that includes physicians, nurses, public health professionals, laboratory technologists, pharmacists, data clerks and volunteer adherence supporters. ART was being provided for children living with HIV regardless of CD4 count and World Health Organization clinical stage classification. Data from zonal health department also showed that A total of 664 children with HIV/AIDS ever enrolled on chronic care in both Hospital and health center since January 2009, but 460 ever start ART in Arba Minch General Hospital and 148 children ever start ART in Arba Minch Health Center (annual report 2016).

\section{Study Design}

An institutional-based retrospective cohort study was conducted to assess incidence and identify predictors of mortality among children on Anti-retroviral therapy in Public health facilities of Arbaminch town, Southern Ethiopia.

\section{Source and study populations}

All HIV infected children being on ART and registered for chronic care in public health facilities of Arba-Minch town providing ART service between 2009 to 2016 were the source populations. All children living with HIV/AIDS whose age $\leq 14$ years being on ART and registered for chronic care at public health institution of Arba Minch town providing ART service from $1^{\text {st }}$ January 2009 to $30^{\text {th }}$ December 2016 were study populations.

\section{Inclusion criteria and exclusion criterion}

All children living with HIV/AIDS whose age $\leq 14$ years being on ART and registered for chronic care at public health institution of Arba Minch town from $1^{\text {st }}$ January 2009 to $30^{\text {th }}$ December 2016 were included, but Children living with HIV/AIDS with incomplete intake form at least with baseline $\mathrm{CD} 4, \mathrm{WHO}$ staging and basic personal information were excluded.

\section{Sample size determination}

The sample size was calculated by applying two population proportion formula using Epi-Info Version 7. Co-trimoxazol preventive therapies, TB co-infection at baseline and anemia were considered. The most significant predictor of Mortality Anemia was used which was taken from the study conduct in Northwest Ethiopia [17] and the following assumption were considered, 95\% CI, power $80 \%$, ratio of unexposed to exposed $1: 1$ and parameters outcome in exposed (Hemoglobin $<10 \mathrm{gm} / \mathrm{dl}$ ) $=14.56 \%$,outcome in unexposed (Hemoglobin $\geq 10 \mathrm{gm} / \mathrm{dl})=5.76 \%$ and $\mathrm{HR}=2.53$. Accordingly, the calculated sample size was 412 . Since we include all 421 samples in our analysis.

\section{Sampling procedure and sampling techniques}

In this study, secondary data from Public health facilities of ArbaMinch town was used to retrieve data from initial date of ART up to the end of the follow up. In this study, the sampling frames are those who had registered for chronic care during data retrieval period of eight consecutive years from January 2009 to December 2016 in Public health facilities of Arba-Minch town. Finally, All HIV-positive children on care and support follow up who had started ART at Public health facilities of Arba-Minch town and fulfill the inclusion criteria were selected (Figure 1).

\section{Data Collection Procedure and Data Quality Control}

The standard data extraction tools was prepared in English which is adapted from the revised 2014 federal ministry of health HIV care/ART follow up form which was used in the ART clinic [11]. Further by using different peer reviewed published literatures $[7,17,18]$. The data extraction format includes socio-demographic characteristics, clinical related information, immunological information, ART \& chemoprophylaxis related information. The data was collected by nine diploma health professionals and supervise by 
four health professionals who have Bachelor of Science as well who were trained on comprehensive HIV care to ensure the quality of data. The data was collected by reviewing the patient's medical cards (follow up and ART intake form) and ART electronic database, but no contact was made with any child so as to maintain privacy and confidentiality. Data on deaths of the HIV positive children while on ART was obtained from health professional report on the medical cards.

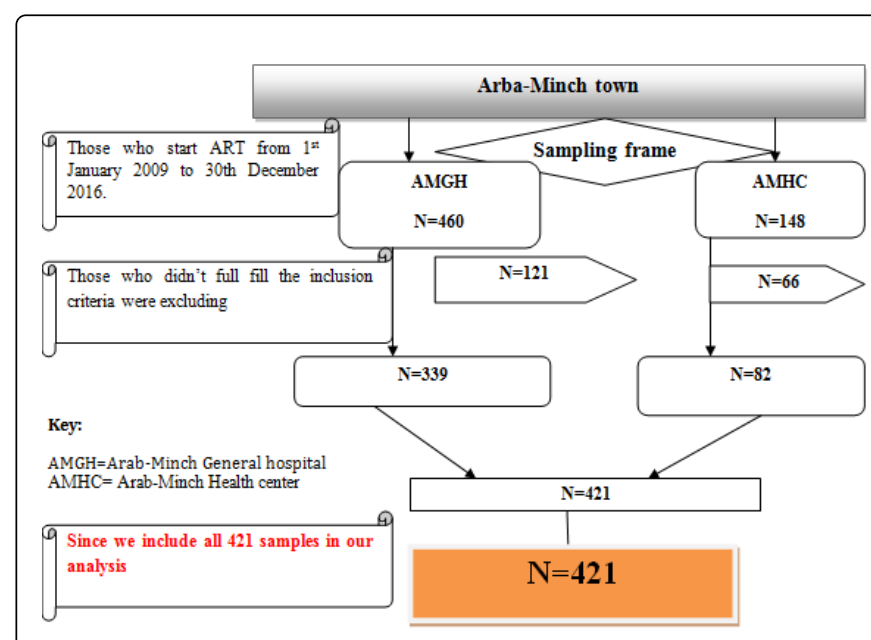

Figure 1: Schematic presentation of sampling procedure for cohort of children start ART between $1^{\text {st }}$ January, 2009 up to 30th December, 2016 in public Health facilities of Arba-Minch town, Gamo Gofa Zone, Southern Ethiopia, March, 2017.

Besides, for those children who died at home, the drug adherence counselor communicated using the contact address and confirmed whether the children were alive or dead. The most recent laboratory results before ART initiation was use as a base line values. If there was no pre-treatment laboratory test, however, results obtained within one month of ART initiation was considered as baseline values. Data collectors and supervisor was trained for one days on objectives of the study, how to select study participants card, how to keep confidentiality of information, the contents of the questionnaire, how to filling on data collection format and data quality management by the principal investigator. The principal investigator and supervisor were conduct a day-to-day follows up during the whole period of data collection. Every day after data collection of the data each questionnaire was reviewed and checked for completeness by the supervisor and the principal investigator and the necessary feedback was given to the data collectors to the next day. The overall activity was supervised by the principal investigator of the study.

\section{Data Processing and Analysis}

The data collection form was checked for completeness and consistency by the principal investigator before data entry. Completed data abstraction form was coded by numbers and entered in computer software Epi-info version 7 and exported to STATA version 11 statistical packages for analysis. Exploratory data analysis was carried out to check the levels of missing values, presence of influential outliers, HIV status of care giver and viral load were highly missing and ART related side effect was highly collinear with ART regimen all were excluded. Descriptive statistics such as median, mean, standard deviation and proportions was used to describe the characteristics of cohort. Incidence of death with respect to person time at risk was calculated and reported as number of death per 1000 Person-months/ years of follow up by assessing the date of enrolment for ART and death or censoring. Life table was used to estimate the cumulative survival of children and kaplan meier survival curve together with log rank test was used to compare survival between different categories of independent variables. Bivariate and Multivariate Cox proportional hazards model were used to identify predictors. Multivariate Cox analysis was done and Hazard ratio, with 95\% CI and P-value was used to assess the strength of association and statistical significance. Variables significant at $\mathrm{P}<0.20$ level in the bivariate analysis [22] were included in the final multivariate Cox- regression analysis, to identify independent predictors of mortality.

Model was built by backward step wise procedure and compared by likely hood ratio test and harrell's concordance statistics test. Interactions and confounders were tested and cut-off point beta change greater than $20 \%$ used. Before fitting the covariate into the model all the Proportionality assumption was tested by global test based on scheonfeld residuals and by examining log minus log plots. The overall goodness of model fitness was checked by Nelson Aalen cumulative hazard function against Cox Snell residual. Multi- co linearity was checked using Pearson correlation, tolerance or variance inflation factor. In order to decide whether or not a variable is significantly associations with mortality were estimated with p-value less than 0.05 the final model. The crude and adjusted hazard ratios together with their corresponding $95 \%$ confidence intervals computed and interpreted accordingly. Nutritional status was defined by ENA for SMART software for generating $\mathrm{Z}$ score.

\section{Ethical considerations}

Ethical approval was obtained from ethical review committee of Arba Minch University, College of Medicine and Health Sciences with reference number CMHS/4268/09. Following the approval, Official letter of co-operation was written to concerned bodies by the department of Public Health of Arba Minch University. Permission was granted from the Hospital and Health center administrative as per the recommendation letter from the department. Personal identifiers were excluded during data extraction; rather code was used. Since it was secondary data obtaining informed consents from the participants was not possible, but the confidentiality of information was maintained by not recording their name from the chart and the recorded data will not be accessed by a third person except by the principal investigator.

\section{Results}

\section{Socio-demographic characteristics of children}

A total of 421 study participants (children $\leq 14$ years) medical records of children living with HIV/AIDS and who started ART were reviewed for this study. Three hundred thirty nine (80.5\%) and 82 (19.5\%) children cards were recruited from Arba-Minch General Hospital and Arba-Minch Health center, respectively. The age of the children ranges from 3 month to 168 month with a median age of 72 month (IQR=33-108 Month) at the time of ART initiation and almost half $(47.2 \%)$ children had started treatment prior to their fifth birthday. Of the total patients included in the study, More than half 241 (57.2\%) were male and the remaining $180(42.8)$ were female, regarding the presences of parental status, $84(20 \%)$ lost their mother and father, 74 (17.6\%) of the children have lost either of their parents (Table 1). 
Citation: Sidamo NB, Debere MK, Enderis B, Abyu DM (2017) Incidence and Predictors of Mortality among Children on Anti-Retroviral Therapy in Public Health Facilities of Arba Minch Town, Gamo Gofa Zone, Southern Ethiopia; Retrospective Cohort Study. Clinics Mother Child Health 14: 267. doi:10.4172/2090-7214.1000267

Page 4 of 11

\begin{tabular}{|c|c|c|c|c|}
\hline \multirow[b]{2}{*}{ Co-variates } & \multirow[b]{2}{*}{ Categories } & \multicolumn{3}{|c|}{ Survival status } \\
\hline & & $\begin{array}{l}\text { Dead } \\
\text { No (\%) }\end{array}$ & $\begin{array}{l}\text { Censored } \\
\text { No (\%) }\end{array}$ & $\begin{array}{l}\text { Total } \\
\text { No (\%) }\end{array}$ \\
\hline \multirow{2}{*}{ Health facility } & Hospital & $50(14.75)$ & $289(85.25)$ & $339(80.5)$ \\
\hline & Health center & $15(18.29)$ & $67(81.71)$ & $82(19.5)$ \\
\hline \multirow{3}{*}{ Age category } & $<1$ year & $8(26.67)$ & $22(73.33)$ & $30(7.1)$ \\
\hline & $1-5$ years & $16(9.47)$ & $153(90.53)$ & $169(40.1)$ \\
\hline & $5-14$ years & $41(18.47)$ & $181(81.53)$ & $222(52.7)$ \\
\hline \multirow{2}{*}{ Sex } & Male & $30(12.45)$ & $211(87.55)$ & $241(57.2)$ \\
\hline & Female & $35(19.44)$ & $145(80.56)$ & $180(42.8)$ \\
\hline \multirow{4}{*}{ Primary care giver } & Parents & $29(44.62)$ & $239(67.1)$ & $268(63.66)$ \\
\hline & Grand parents & $13(16.67)$ & 65 (83.33) & 78 (18.53) \\
\hline & Orphanage centers & $8(23.53)$ & $26(76.47)$ & $34(8.08)$ \\
\hline & Siblings & 15 (36.59) & $26(63.41)$ & $41(9.73)$ \\
\hline \multirow{4}{*}{ Marital status of care giver $(n=387)$} & Married & $24(11.54)$ & $184(88.46)$ & $208(53.75)$ \\
\hline & Single & $13(28.26)$ & $33(71.74)$ & 46 (11.89) \\
\hline & Divorced & $9(12.5)$ & $63(87.5)$ & $72(18.6)$ \\
\hline & Widowed & $11(18.03)$ & $50(81.97)$ & $61(15.76)$ \\
\hline \multirow{3}{*}{ Care giver HIV sero-status ( $n=387$ ) } & Positive & $26(9.52)$ & $247(90.48)$ & $273(70.54)$ \\
\hline & Negative & $9(23.68)$ & $29(76.32)$ & $38(9.82)$ \\
\hline & Unknown & $22(28.95)$ & $54(71.05)$ & 76 (19.63) \\
\hline \multirow{4}{*}{ Parental status } & Both parents are alive & $35(13.46)$ & $225(86.54)$ & $260(61.76)$ \\
\hline & Maternal orphan & $9(20)$ & $36(80)$ & $45(10.69)$ \\
\hline & Paternal orphan & $6(19.35)$ & $25(80.65)$ & $31(7.36)$ \\
\hline & Double orphan & $15(17.86)$ & 69 (82.24) & $84(19.95)$ \\
\hline
\end{tabular}

Table 1: Baseline socio-demographic characteristics of children on ART at Public health facilities of Arba-Minch town, Gamo Gofa Zone, Southern Ethiopia, March, 2017.

\section{Baseline clinical and immunological characteristic of children}

Clinically 196 (47\%) children initiated ART at an advanced stage of the disease i.e. WHO clinical stage III or IV. About $108(25.7 \%)$ of children were at delayed developmental milestone status during ART initiation. One hundred ninety eight (47\%) of them were malnourished among those $14.74 \%$ of children have several acute malnourished at initiation of ART. During the ART initiation 139 (33.02\%) of children were affected by one or more opportunistic illness, of which 41 children found to be dead at the end of the study. Additionally 60 (14.25\%) had history of Tuberculosis at the start of ART and 36 were died during the follow up time. At the initiation of ART, mean (SD) values for weight of children was $18.61( \pm 9.65) \mathrm{kg}$ and mean (SD) values for height of the cohort was $110.79( \pm 32.19) \mathrm{cm}$. The base line median values for $\mathrm{Hgb}$ was $10.9(\mathrm{IQR}=8.8-12.3) \mathrm{g} / \mathrm{dl}$. Similarly 181
(43.1\%) of the children had absolute CD4 count below threshold for immune deficiency at initiation of ART (Table 2).

\section{Baseline ART and chemoprophylaxis status of children on ART}

Among the reviewed participants 407 (96.67\%) were on first line ART regiment while the rest started on second line. Concerning the type of ART regimens around $59.6 \%$ of children were taking D4T based drug regimens while they start treatment. The majority, (56.1\%) children had regimen substitution their initial regimen during the follow up period mainly to a combination of AZT+3TC+NVP (4c) 122 (29\%) and $27(11.44 \%)$ patients were switched to second line ART. Among the study participant 152 (36.1\%) of children are develop ART related side effect 335 (79.6\%) children had good adherence for ART, 
Citation: Sidamo NB, Debere MK, Enderis B, Abyu DM (2017) Incidence and Predictors of Mortality among Children on Anti-Retroviral Therapy in Public Health Facilities of Arba Minch Town, Gamo Gofa Zone, Southern Ethiopia; Retrospective Cohort Study. Clinics Mother Child Health 14: 267. doi:10.4172/2090-7214.1000267

Page 5 of 11

$314(74.6 \%)$ were taking CPT and $302(71.7 \%)$ were taking INH prophylaxis therapy at ART initiation (Table 3).

\begin{tabular}{|c|c|c|c|c|}
\hline \multirow[b]{2}{*}{ Co-variates } & \multirow[b]{2}{*}{ Categories } & \multicolumn{3}{|c|}{ Survival status } \\
\hline & & $\begin{array}{l}\text { DEAD } \\
\text { No (\%) }\end{array}$ & $\begin{array}{l}\text { Censored } \\
\text { No (\%) }\end{array}$ & $\begin{array}{l}\text { Total } \\
\text { No (\%) }\end{array}$ \\
\hline \multirow{3}{*}{$\begin{array}{l}\text { Developmental } \\
\text { milestone }\end{array}$} & Appropriate & $16(5.99)$ & $\begin{array}{l}251 \\
(94.01)\end{array}$ & $267(63.4)$ \\
\hline & Delayed & $\begin{array}{l}22 \\
(20.37)\end{array}$ & $86(79.63)$ & $108(25.7)$ \\
\hline & Regressed & $\begin{array}{l}27 \\
(58.70)\end{array}$ & $19(41.30)$ & $46(10.9)$ \\
\hline \multirow{4}{*}{$\begin{array}{l}\text { Baseline WHO } \\
\text { clinical staging }\end{array}$} & Stage I & $9(9.89)$ & $82(90.11)$ & $91(21.62)$ \\
\hline & Stage II & $12(8.96)$ & $\begin{array}{l}122 \\
(91.04)\end{array}$ & $\begin{array}{l}134 \\
(31.83)\end{array}$ \\
\hline & Stage III & $\begin{array}{l}20 \\
(13.51)\end{array}$ & $\begin{array}{l}128 \\
(86.49)\end{array}$ & $\begin{array}{l}148 \\
(35.15)\end{array}$ \\
\hline & Stage IV & $24(50)$ & $24(50)$ & $48(11.40)$ \\
\hline \multirow{4}{*}{$\begin{array}{l}\text { Baseline } \\
\text { Nutritional status }\end{array}$} & Normal & $\begin{array}{l}28 \\
(12.39)\end{array}$ & $\begin{array}{l}195 \\
(87.61)\end{array}$ & $\begin{array}{l}223 \\
(52.97)\end{array}$ \\
\hline & Mild & $8(15.09)$ & 45 (84.91) & 53 (12.59) \\
\hline & MAM & $11(13.25)$ & 72 (86.75) & $83(19.7)$ \\
\hline & SAM & $\begin{array}{l}18 \\
(29.03)\end{array}$ & $44(70.97)$ & $62(14.74)$ \\
\hline \multirow{2}{*}{$\begin{array}{l}\text { Opportunistic } \\
\text { Infections } \\
\text { baseline }\end{array}$} & Yes & $\begin{array}{l}41 \\
(29.50)\end{array}$ & $98(70.50)$ & $\begin{array}{l}139 \\
(33.02)\end{array}$ \\
\hline & No & $24(8.52)$ & $\begin{array}{l}258 \\
(91.48)\end{array}$ & $\begin{array}{l}282 \\
(66.98)\end{array}$ \\
\hline \multirow{2}{*}{$\begin{array}{l}\text { TB co-infection at } \\
\text { baseline }\end{array}$} & Yes & $36(60)$ & $24(40)$ & $60(14.25)$ \\
\hline & No & $29(8.03)$ & $\begin{array}{l}332 \\
(91.07)\end{array}$ & $\begin{array}{l}361 \\
(85.75)\end{array}$ \\
\hline \multirow{3}{*}{$\begin{array}{l}\text { Baseline } \quad \text { Viral } \\
\text { Load }\end{array}$} & Undetectable & $\begin{array}{l}20 \\
(12.99)\end{array}$ & $\begin{array}{l}134 \\
(87.01)\end{array}$ & $154(36.6)$ \\
\hline & Detectable & $\begin{array}{l}23 \\
(21.10)\end{array}$ & 86 (78.89) & $109(25.9)$ \\
\hline & Not done & $\begin{array}{l}22 \\
(13.92)\end{array}$ & $\begin{array}{l}136 \\
(86.08)\end{array}$ & $158(37.5)$ \\
\hline \multirow{2}{*}{ Hemoglobin } & $<10 \mathrm{gm} / \mathrm{dl}$ & $\begin{array}{l}35 \\
(44.87)\end{array}$ & $43(55.13)$ & $78(18.5)$ \\
\hline & $\geq 10 \mathrm{gm} / \mathrm{dl}$ & $30(8.75)$ & $\begin{array}{l}313 \\
(91.25)\end{array}$ & $343(81.5)$ \\
\hline \multirow{2}{*}{ Absolute CD4 } & $\begin{array}{ll}\text { CD4 } & \text { above } \\
\text { threshold } & \end{array}$ & $27(11.25)$ & $\begin{array}{l}213 \\
(88.75)\end{array}$ & $240(57)$ \\
\hline & $\begin{array}{ll}\text { CD4 below } \\
\text { threshold }\end{array}$ & $\begin{array}{l}38 \\
(20.98)\end{array}$ & $\begin{array}{l}143 \\
(79.02)\end{array}$ & $181(43)$ \\
\hline
\end{tabular}

Table 2: Baseline clinical and immunological status of children on ART in Public health facilities of Arba-Minch town, Gamo Gofa Zone, Southern Ethiopia, March, 2017.

\section{Incidence of mortality after initiation of ART}

Out of the 421 cohort of children on ART, 261 (62\%) children were alive, $43(10.2 \%)$ were lost to follow-up, $52(12.4 \%)$ were transferred out to other facilities and $65(15.4 \%)$ were reported dead. Out of the 65 mortality $14(21.5 \%)$ died within the first 6 month, $10(15.4 \%)$ in the 36 month and $11(16.9 \%)$ in the 60 month. After initiation of ART, children were followed for different periods; a minimum of 1 month and a maximum of 95 month with median follow up period of 50 months with IQR of 24 to 80 months and the cohort contributed to a total of 21,175 person-months (1764.58 person-years) of follow up. The overall mortality rate of the cohort was found to be $3.07(95 \%$ $\mathrm{CI}=2.37-3.91)$ per 1000 person-months of observation or 36.8 per 1000 person-year of observation.

\begin{tabular}{|c|c|c|c|c|}
\hline \multirow[b]{2}{*}{ Co-variates } & \multirow[b]{2}{*}{ Categories } & \multicolumn{3}{|c|}{ Survival status } \\
\hline & & $\begin{array}{l}\text { DEAD } \\
\text { No (\%) }\end{array}$ & $\begin{array}{l}\text { Censored } \\
\text { No (\%) }\end{array}$ & $\begin{array}{l}\text { Total } \\
\text { No (\%) }\end{array}$ \\
\hline \multirow{4}{*}{$\begin{array}{l}\text { ART Regimens } \\
\text { at baseline }\end{array}$} & D4T-based regimen & $33(13.14)$ & $218(86.86)$ & $\begin{array}{l}251 \\
(59.62)\end{array}$ \\
\hline & AZT-based regimen & $16(14.81)$ & $92(85.19)$ & $\begin{array}{l}108 \\
(25.65)\end{array}$ \\
\hline & $\begin{array}{l}\text { TDF-based } \\
\text { regimen }\end{array}$ & $10(20.83)$ & $38(79.17)$ & $48(11.40)$ \\
\hline & 2nd line & $6(42.86)$ & $8(57.14)$ & $14(3.33)$ \\
\hline \multirow{3}{*}{$\begin{array}{l}\text { ART Adherence } \\
\text { on follow up }\end{array}$} & Good & $29(8.66)$ & 306 (91.34) & 335 (79.6) \\
\hline & Fair & $15(45.45)$ & $18(54.55)$ & $33(7.8)$ \\
\hline & Poor & 21 (39.62) & $32(60.38)$ & $53(12.6)$ \\
\hline \multirow{2}{*}{$\begin{array}{l}\text { Regimen } \\
\text { Substitution }\end{array}$} & Yes & $21(8.90)$ & $215(91.10)$ & $236(56.1)$ \\
\hline & No & $44(23.78)$ & $141(76.22)$ & $185(43.9)$ \\
\hline \multirow{2}{*}{$\begin{array}{l}\text { ART drug side } \\
\text { effect }\end{array}$} & Yes & $41(26.97)$ & $111(73.03)$ & $152(36.1)$ \\
\hline & No & $24(8.92)$ & $245(91.08)$ & 269 (63.9) \\
\hline \multirow{2}{*}{$\begin{array}{l}\text { Cotrimoxazol } \\
\text { prophylaxis }\end{array}$} & Yes & $24(7.64)$ & 290 (92.36) & 314 (74.6) \\
\hline & No & $41(38.32)$ & 66 (61.68) & $107(25.4)$ \\
\hline \multirow{2}{*}{ INH prophylaxis } & Yes & $28(9.27)$ & 274 (90.73) & $302(71.7)$ \\
\hline & No & 37 (31.09) & $82(68.91)$ & $119(28.3)$ \\
\hline
\end{tabular}

Table 3: Baseline ART and chemoprophylaxis related factors among children on ART in Public health facilities of Arba-Minch town, Gamo Gofa Zone, Southern Ethiopia, March, 2017.

Out of the 65 mortality cases, highest incidence rate of death was observed within 6 months of the ART initiation 14 (7.93 per 1000 child year of observation) but, 19 (0.89 per 1000 Person-months) died within 12 months of ART initiation while 46 (2.17 per 1000 Personmonths) died after 12 months. The overall mean estimated survival time of the children under the study was 82.32 month with $95 \%$ confidence interval that as high as 85.14 month and as small as 79.48 month after ART initiation. The cumulative probability of survival at the end of $6^{\text {th }}, 12^{\text {th }}, 24^{\text {th }}, 60^{\text {th }}$ and $96^{\text {th }}$ month was $96.6 \%, 95.9 \%, 93.4 \%$, $82.9 \%$ and $73.9 \%$ respectively. The cumulative survival after $96^{\text {th }}$ months was $73.9 \%$ (Table 4 and Figure 2). 
Citation: Sidamo NB, Debere MK, Enderis B, Abyu DM (2017) Incidence and Predictors of Mortality among Children on Anti-Retroviral Therapy in Public Health Facilities of Arba Minch Town, Gamo Gofa Zone, Southern Ethiopia; Retrospective Cohort Study. Clinics Mother Child Health 14: 267. doi:10.4172/2090-7214.1000267

Page 6 of 11

\section{Comparison of survival probability among categories of covariates}

Kaplan Meier survival curve together with log rank test was used to check for the existence of any significant differences in survival probability between the various categories of variables considered in this study. Accordingly, Children that initiated ART at advanced stage of the disease (WHO stage III \& IV) progression had significantly lower survival probability compared to those who start early in the disease progression $(\log$ rank, $\mathrm{P}<0.05)$. The survival probability for children with low hemoglobin level $(<10 \mathrm{gm} / \mathrm{dl})$ were significantly lesser survival probability compared to those with higher hemoglobin level (log rank, $\mathrm{P}<0.05)$.

\begin{tabular}{|c|c|c|c|c|c|}
\hline $\begin{array}{c}\text { Time in } \\
\text { Month }\end{array}$ & $\begin{array}{c}\text { No of children at } \\
\text { start }\end{array}$ & $\begin{array}{c}\text { Number of } \\
\text { deaths }\end{array}$ & $\begin{array}{c}\text { Survival } \\
\text { function }\end{array}$ & \multicolumn{2}{|c|}{$(95 \%$ CI) } \\
\hline 6 & 421 & 14 & 0.966 & 0.943 & 0.979 \\
\hline 12 & 391 & 5 & 0.959 & 0.934 & 0.974 \\
\hline 24 & 342 & 4 & 0.934 & 0.904 & 0.954 \\
\hline 36 & 287 & 4 & 0.905 & 0.87 & 0.931 \\
\hline 48 & 237 & 5 & 0.854 & 0.811 & 0.888 \\
\hline 60 & 204 & 4 & 0.829 & 0.782 & 0.867 \\
\hline 72 & 172 & 2 & 0.825 & 0.755 & 0.847 \\
\hline 84 & 117 & 0 & 0.782 & 0.726 & 0.827 \\
\hline 96 & 36 & 1 & 0.739 & 0.632 & 0.819 \\
\hline
\end{tabular}

Table 4: Actuarial life table cumulative survival of children after start of ART at a specific time, Public Health facilities of Arba-Minch town, Gamo Gofa Zone, Southern Ethiopia, March, 2017.

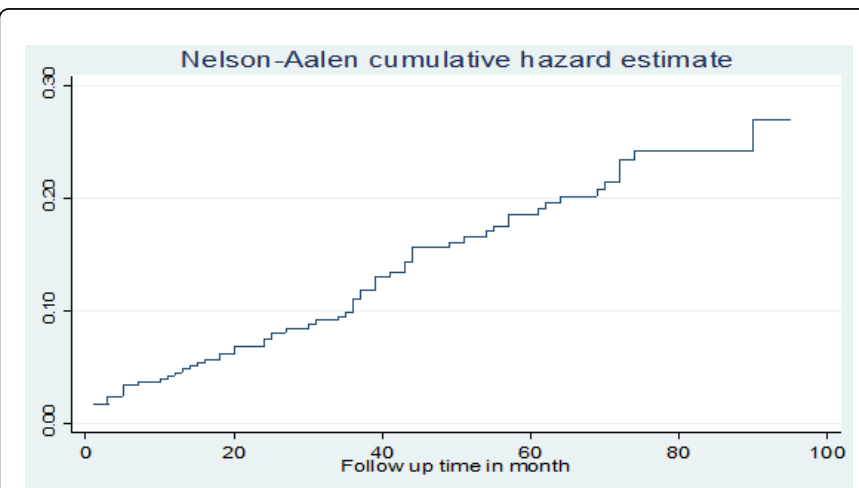

Figure 2: Nelson-Alen cumulative hazard of children on ART at Public Health facilities of Arba-Minch town, Gamo Gofa Zone, Southern Ethiopia, March, 2017.

Children on ART that had evidence of TB co-infection at initiation of ART as well as after they start ART had lesser survival probability compared to those with no evidence of TB ( $\log$ rank, $\mathrm{P}<0.05)$. Children on ART that had OI at baseline had lesser survival probability compared to those with no OI at baseline (log rank, $\mathrm{P}<0.05)$. Children on ART who had taken CPT and INH prophylaxis have significantly higher survival probability compared to those who did not taken those prophylaxis (log rank, $\mathrm{P}<0.05$ ). However, the $\mathrm{p}$-values of the log-rank test don't showed that the mean survival experience of patients among those categories of sex, type of health institution and Absolute CD4 count (The log rank test result is shown in Figures 3 and 4).

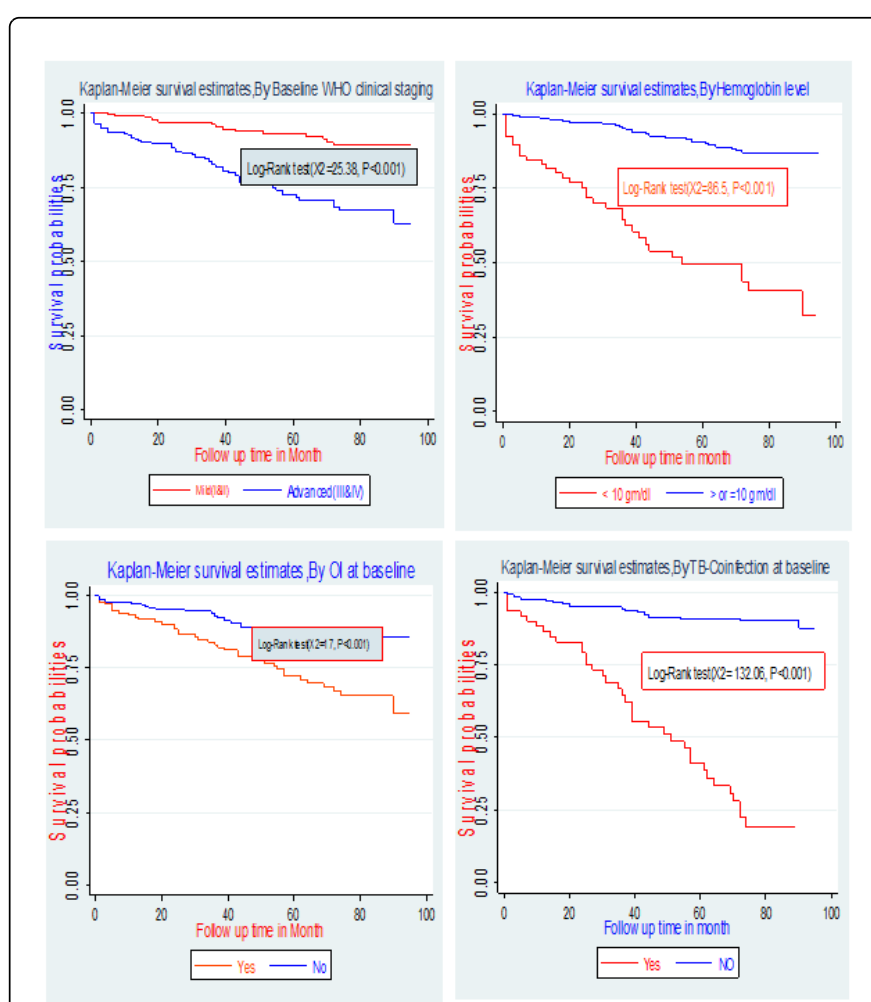

Figure 3: Survival curves for children on ART according to their WHO clinical stage, OI at baseline, TB-Co-infection Hemoglobin level at public health facilities of Arba-Minch town, Gamo Gofa Zone, Southern Ethiopia, March, 2017.

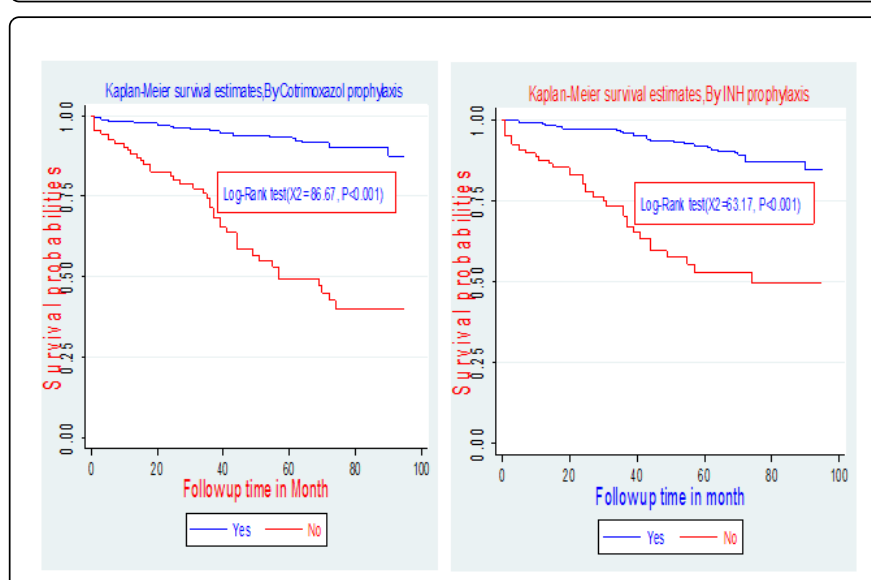

Figure 4: Survival curves for children on ART according to their CPT prophylaxis and INH prophylaxis at public health facilities of Arba-Minch town, Gamo Gofa Zone, Southern Ethiopia, March, 2017. 
Citation: Sidamo NB, Debere MK, Enderis B, Abyu DM (2017) Incidence and Predictors of Mortality among Children on Anti-Retroviral Therapy in Public Health Facilities of Arba Minch Town, Gamo Gofa Zone, Southern Ethiopia; Retrospective Cohort Study. Clinics Mother Child Health 14: 267. doi:10.4172/2090-7214.1000267

Page 7 of 11

\section{Predictors of Mortality after Initiation of ART}

Before fitting the covariate into the model all the proportional hazard assumptions were checked by Schoenfeld residual and by examining log minus log plots no variable were violate the assumption. To identify independent predictors of mortality, a multivariate CoxProportional hazard adjusted model was fitted by forward stepwise procedures with the variables having a P-value less than 0.20 in the bivariate analysis. Multi-colinearity was checked using Pearson correlation, tolerance or variance inflation factor and we found that baseline ART regimen and ART side effect was highly correlated $(r=0.728)$, so that further analysis in the final model were not done.

The risk of mortality was increased among children with baseline opportunistic infections (AHR=1.93, 95\% CI=1.03 to 3.64, $\mathrm{P}=0.041$ ), $\mathrm{TB}$ co infected at ART initiation $(\mathrm{AHR}=2.28,95 \% \mathrm{CI}=1.23$ to 4.22 , $\mathrm{P}=0.009), \quad \mathrm{CD} 4$ count below threshold for immunodeficiency $(\mathrm{AHR}=2.08,95 \% \mathrm{CI}=1.15$ to $3.77, \mathrm{P}=0.016)$, Low hemoglobin level $(<10 \mathrm{gm} / \mathrm{dl}) \quad(\mathrm{AHR}=3.32,95 \% \mathrm{CI}=1.83$ to $6.04, \mathrm{P}=0.001)$ compared with their counter parts. Similarly Children with delayed developmental milestone at initiation of ART (AHR $=4.42,95 \%$ $\mathrm{CI}=1.99$ to $9.75, \mathrm{P}=0.001$ ), as well as children who were regressing developmental milestone at initiation of ART (AHR=6.0 95\% CI=2.68 to $13.45, \mathrm{P}=0.001$ ) more likely to die early as compared to clients with appropriate developmental milestone.

Another important predictor of mortality in this was adherence status of children. The risk of mortality among children who were on poor adherence was nearly two times higher than that of good adherence $(\mathrm{AHR}=2.05,95 \% \mathrm{CI}=1.02$ to $4.13, \mathrm{P}=0.044)$. Similarly the risk of mortality among children who were on fair adherence was 2.17 times higher than that of good adherence (AHR=2.17, 95\% CI $=1.12$ to 4.79, $\mathrm{P}=0.025$ ). Regarding to prophylaxis preventive therapy the estimated AHR for children on INH prophylaxis and CPT prophylaxis was $0.38(\mathrm{AHR}=0.38,95 \% \mathrm{CI}=0.22$ to $0.68, \mathrm{P}=0.001)$ and 0.26 (AHR $=0.2695 \% \mathrm{CI}=0.15$ to $0.46, \mathrm{P}=0.001$ ). This means the death hazard in the among children who take INH prophylaxis were $62 \%$ and those on CPT prophylaxis were $74 \%$ reducing the risk than their counterpart at any given time respectively (Table 5).

\begin{tabular}{|c|c|c|c|c|c|}
\hline \multirow{2}{*}{ Co-variates } & \multicolumn{2}{|c|}{ Survival status } & \multirow[t]{2}{*}{$\mathrm{CHR}(95 \% \mathrm{Cl})$} & \multirow{2}{*}{ AHR $(95 \% \mathrm{Cl})$} & \multirow{2}{*}{ p-value } \\
\hline & Dead & Censored & & & \\
\hline \multicolumn{6}{|l|}{ Sex } \\
\hline Male & 30 & 211 & 1 & & \\
\hline Female & 35 & 145 & $1.62(0.99,2.63)$ & $0.79(0.42,1.52)$ & 0.486 \\
\hline \multicolumn{6}{|l|}{ Age category } \\
\hline$<1$ year & 8 & 22 & $1.59(0.74,3.39)$ & $2.31(0.87,6.13)$ & 0.092 \\
\hline $1-5$ years & 16 & 153 & $0.51(0.29,0.90)^{*}$ & $0.91(0.44,1.88)$ & 0.789 \\
\hline $5-14$ years & 41 & 181 & 1 & & \\
\hline \multicolumn{6}{|c|}{ Baseline Developmental Milestone } \\
\hline Appropriate & 16 & 251 & 1 & & \\
\hline Delayed & 22 & 86 & $4.21(2.21,8.04)^{*}$ & $4.42(1.99,9.75)$ & $0.001^{* *}$ \\
\hline Regressed & 27 & 19 & $16.51(8.84,30.85)^{*}$ & $6.00(2.68,13.45)$ & $0.001^{\star \star}$ \\
\hline \multicolumn{6}{|c|}{ Baseline Nutritional status } \\
\hline Normal & 28 & 195 & 1 & & \\
\hline Mild & 8 & 45 & $0.77(0.29,2.00)$ & $1.74(0.59,5.08)$ & 0.312 \\
\hline MAM & 11 & 72 & $1.1(0.60,2.42)^{\star}$ & $1.76(0.77,4.03)$ & 0.181 \\
\hline SAM & 18 & 44 & $2.48(1.41,4.38)^{*}$ & $1.27(0.61,2.65)$ & 0.53 \\
\hline \multicolumn{6}{|c|}{ Baseline WHO clinical staging } \\
\hline Mild (I\&II) & 21 & 204 & 1 & & \\
\hline Advanced (III\&IV) & 44 & 152 & $3.49(2.21,7.01)^{*}$ & $1.38(0.68,2.77)$ & 0.372 \\
\hline \multicolumn{6}{|l|}{ Ols at baseline } \\
\hline Yes & 41 & 98 & $2.70(1.65,4.42)^{*}$ & $1.93(1.03,3.64)$ & $0.041^{\star *}$ \\
\hline No & 24 & 258 & 1 & 1 & \\
\hline
\end{tabular}


Citation: Sidamo NB, Debere MK, Enderis B, Abyu DM (2017) Incidence and Predictors of Mortality among Children on Anti-Retroviral Therapy in Public Health Facilities of Arba Minch Town, Gamo Gofa Zone, Southern Ethiopia; Retrospective Cohort Study. Clinics Mother Child Health 14: 267. doi:10.4172/2090-7214.1000267

Page 8 of 11

\begin{tabular}{|c|c|c|c|c|c|}
\hline \multicolumn{6}{|c|}{ TB co-infection at baseline } \\
\hline Yes & 36 & 24 & $10.56(6.41,17.42)^{*}$ & $2.28(1.23,4.22)$ & $0.009^{*}$ \\
\hline No & 29 & 332 & 1 & 1 & \\
\hline \multicolumn{6}{|l|}{ Hemoglobin at baseline } \\
\hline$<10 \mathrm{gm} / \mathrm{dl}$ & 35 & 43 & $7.29(4.47,11.92)^{*}$ & $3.32(1.83,6.04)$ & $0.001^{\star *}$ \\
\hline$\geq 10 \mathrm{gm} / \mathrm{dl}$ & 30 & 313 & 1 & 1 & \\
\hline \multicolumn{6}{|l|}{ Absolute CD4 } \\
\hline CD4 above threshold & 27 & 213 & 1 & 1 & \\
\hline CD4 below threshold & 38 & 143 & $1.67(1.02,2.74)^{*}$ & $2.08(1.15,3.77)$ & $0.016^{* *}$ \\
\hline \multicolumn{6}{|c|}{ ART Adherence on follow up } \\
\hline Good & 29 & 306 & 1 & 1 & \\
\hline Fair & 15 & 18 & $6.23(3.35,11.70)^{*}$ & $2.17(1.12,4.79)$ & $0.025^{* *}$ \\
\hline Poor & 21 & 32 & $5.94(3.38,10.44)^{*}$ & $2.05(1.02,4.13)$ & $0.044^{\star *}$ \\
\hline \multicolumn{6}{|l|}{ CPT prophylaxis } \\
\hline Yes & 24 & 290 & $0.12(0.07,0.20)^{*}$ & $0.26(0.15,0.46)$ & $0.001^{\star *}$ \\
\hline No & 41 & 66 & 1 & 1 & \\
\hline \multicolumn{6}{|l|}{ INH prophylaxis } \\
\hline Yes & 28 & 274 & $0.17(0.10,0.27)^{*}$ & $0.38(0.22,0.68)$ & $0.001^{\star \star}$ \\
\hline No & 37 & 82 & 1 & 1 & \\
\hline
\end{tabular}

Table 5: Bivariate and multivariate cox proportional hazard analysis for predictors of mortality among children on ART at public health facilities of Arba-Minch town, Gamo Gofa Zone, Southern Ethiopia, March, 2017.

\section{Discussion}

This study assessed incidence and predictors of mortality among children on ART in public health facilities of Arba-Minch town. A total of 421 children were followed for 21175 person-month of observation. During the follow up period 65 (15.4\%) died making overall incidence density rate of 3.07 (95\% CI=2.37-3.91) per 1000 person-months of observation. Survival probabilities at the end of $6^{\text {th }}$, $12^{\text {th }}, 24^{\text {th }}, 60^{\text {th }}$ and $96^{\text {th }}$ month was $96.6 \%, 95.9 \%, 93.4 \%, 82.9 \%$ and $73.9 \%$ respectively and overall mean survival time was 82.32 month. (95\% CI: 79.48-85.14). Delayed/regressed developmental milestone, OI at baseline, TB co infection at baseline, low hemoglobin level, absolute CD4 below threshold, poor/fair adherence to ART were factors increased occurrence mortality. However, the preventive factors were taking INH prophylaxis and cotrimoxazole prophylaxis.

The findings of this study showed that, the overall incidence of mortality rate of 3.07 (95\% CI=2.37-3.91) per 1000 person-months of observation. This finding was comparable from study conducted of eastern Ethiopia (3.8 per 1000 person-months of observation), south west Ethiopia (2.5 per 1000 person-months of observation) and study conduct in Cameron (2.43 per 1000 person-months of observation) $[16,21,23]$. But lower than finding of Kenya (7 per 1000 person-months of observation) and south Africa (3.95 per 1000 person-months of observation) $[12,23,24]$. However, this finding was higher than the finding of study conduct Northern Ethiopia (1.40 per 1000 personmonths of observation) and Nigeria ( 0.97 per 1000 person-months of observation) $[15,18]$. These variations might be explained in three ways. Firstly, the difference could be longer follow-up period than study conducted previously. Secondly it might be related to expansion ART program was significantly reducing deaths among AIDS children proves that the ART program is functioning well. Thirdly it might be associated with effect of INH which prevents the occurrence of OIs like $\mathrm{TB}$ and life-threatening bacterial infections.

The finding of this study revealed that mean survival time of cohort under the study was 82.32 month (95\% CI=79.48-85.14). This finding was in line with a study conduct in Southwest Ethiopia 83 months (95\% CI=79-87) [21]. However, this finding was higher when compared with study from conduct in Northwest Ethiopia 56.5 months, Felege-Hiwot Referral Hospital 22.4 months and study conduct in Zewditu memorial hospital Ethiopia 27.9 months $[18,20,25]$. This discrepancy might be associated with high proportion (74.3\%) of children in our study taken CPT prophylaxis as compared to the other finding conduct in Ethiopia (52.3\%-70.4\%) another it may associated with increased access of ART services. 
Citation: Sidamo NB, Debere MK, Enderis B, Abyu DM (2017) Incidence and Predictors of Mortality among Children on Anti-Retroviral Therapy in Public Health Facilities of Arba Minch Town, Gamo Gofa Zone, Southern Ethiopia; Retrospective Cohort Study. Clinics Mother Child Health 14: 267. doi:10.4172/2090-7214.1000267

Page 9 of 11

The cumulative probability of survival children on ART in this study was $82.9 \%$ after 5 years (95\% CI: $78.2 \%-86.7 \%$ ). This finding was comparable from study conducted in Felege hiwot referral hospital Bahir Dar, Ethiopia 83\% and finding conducted in Northwest Ethiopia $83 \%[18,20]$. However this finding was much lower than findings from Adama referral hospital and medical college, Ethiopia (91.6\%) and study conducted in wolaita zone health facilities $(92 \%)[7,19]$. These variations might be this study include health center and general hospital, but previously study were conduct in referral hospital, so health centers have most of simple cases as severe cases were refer to hospital secondly it might be related to type of care provided vary from institution to institution.

In multivariate Cox proportional hazard model revealed that CPT prophylaxis, INH prophylaxis, low baseline hemoglobin, absolute CD4 count below the threshold, OIs at baseline, TB co infection at baseline, delayed or regressing baseline developmental milestones and adherence to ART were predictors of mortality.

The finding of this study revealed that higher risk of mortality was found among children who had regressing developmental milestone at initiation of ART. The HR for death among children who had regressing developmental milestone at initiation of ART were 6 times (CI: $2.68,13.45)$ more likely to die early as compared to appropriate developmental milestone. As well as the risk of earlier death was 4.42 times $(\mathrm{AHR}=4.42,95 \% \mathrm{CI}=1.99$ to $9.75, \mathrm{P}=0.001)$ higher for children who have delayed developmental milestone than children who have appropriate developmental milestone. This finding was support by study conduct in North West Ethiopia and study conduct in Kenya $[12,17]$. This is might explained in three form be due to first developmental milestone was related to cognitive development of children and high HIV virus was high cognitive effects on children. Secondly it might related to children with HIV are subject to the potential impact of the virus which reduced stimulation. Thirdly it might associated with burdens of HIV and AIDS in families, such as stigma, orphan-hood or severe parental illness, caretaker changes, separation and poverty.

In this study we found that having CD4 cell count below the threshold level was significantly associated with an increased incidence of mortality. Therefore, children with absolute CD4 count below the threshold level for immunodeficiency at initiation of ART was 2.08 times $(\mathrm{AHR}=2.08,95 \% \mathrm{CI}=1.15$ to $3.77, \mathrm{P}=0.016)$ more likely to be become died at any time than whose baseline CD4 count above threshold. The finding was supported by different study done in Ethiopia [17-19]. This similarity might be related to children with absolute CD4 count below the threshold level were more prone to opportunistic infections, like tuberculosis. Another explanation might be due to starting ART in advanced stage (III \& IV) will reduce immunity may lead to immune compromised.

The risk of death in children who have low hemoglobin level $(<10$ $\mathrm{gm} / \mathrm{dl})$ was all most 3.32 times $(\mathrm{AHR}=3.32,95 \% \mathrm{CI}=1.83$ to 6.04 , $\mathrm{P}=0.001)$ higher than those who have normal hemoglobin level. This finding is in line with finding of study conduct in Adama referral hospital, Felege hiwot referral hospital, Kenya and rural hospital of Tanzania $[12,13,19,20]$.

This discrepancy could be explained in three ways. The first it might relate to side effect associated with AZT based ART regimen. Secondly it might associate with presence of severe immunodeficiency which was indicator of late presentation for health care, resulting in late HIV diagnosis and treatment which could lead to poorer outcomes. Lastly it might be associated with malnutrition. Majority of our study participant $(47 \%)$ were affect by malnutrition. In our study, though severe malnutrition was not an independent predictor of mortality in the multivariate Cox regression modeling; it was associated with mortality in the bivariate modeling. This finding contrasts the finding of study in Kenya $[6,12,26]$.

The another co-variates that have a significant effect on incidence of mortality was adherence to ART when adherence to ART assed by counting number of table those children miss within the first three month after staring of ART. The HR for poor adherence was 2.05 times and HR for fair adherence was 2.17 times more likely to die early than when we compare to children good adherence (AHR $=2.05,95 \%$ $\mathrm{CI}=1.02$ to $4.13, \mathrm{P}=0.044)$ and $(\mathrm{AHR}=2.17,95 \% \mathrm{CI}=1.12$ to 4.79 , $\mathrm{P}=0.025$ ) respectively. This finding was supported by studies conducted in north west Ethiopia, Wolaita zone health facilities and Eastern Ethiopia [7,16,27]. The possible reason for higher risk of mortality might be explained in three reason, The first may be due to staff as well as adherence supporters is not provided regular counseling and caregiver/patient education that are critical for the supportive care of HIV-infected children. Secondly might be those children with fair/ poor adherence are much more to development of ART related side effect in our study ART related side effect is also significantly associated with early mortality among those children. Thirdly might be those children lack of appreciation that drugs can help persons who are asymptomatic, thus may increase to the development of drugresistant.

The finding of this study revealed that those children who have opportunistic infections at a baseline is 1.93 times (AHR $=1.93,95 \%$ $\mathrm{CI}=1.03$ to $3.64, \mathrm{P}=0.041$ ) more likely to die early than those without opportunistic infections. Similarly, those children with a history of TB co-infection at base line were 2.28 times $(\mathrm{AHR}=2.28,95 \% \mathrm{CI}=1.23$ to $4.22, \mathrm{P}=0.009$ ) at higher risk of death than those without it during the follow-up period. This finding was support by the finding of study conducted in South Africa, Tanzania, Nigeria and Ethiopia $[13,15,21,24]$.

The effect of CPT and INH at the time of starting of ART among cohort suggested a lower risk of mortality. Being put the children on cotrimoxazole prophylaxis were 0.26 ( $\mathrm{AHR}=0.2695 \% \mathrm{CI}=0.15$ to 0.46 , $\mathrm{P}=0.001)$. This means risk of death in patients with CPT prophylaxis were $74 \%$ reduced the hazard of early death than their counterpart throughout the follow-up time. This finding was supported by studies conducted in Felege hiwot referral hospital Ethiopia and Zambian $[17,28]$.

The hazards of death for children on INH prophylaxis was 0.38 (AHR $=0.38,95 \% \mathrm{CI}=0.22$ to $0.68, \mathrm{P}=0.001$ ). This means at those children who take INH prophylaxis were $62 \%$ reduced the hazard of early death than their counterpart throughout the follow-up time. This finding is agreed with the finding of the study conducted in MizanAman general hospital, Ethiopia and South Africa $[21,24]$. The possible reason may be INH prophylactic therapy was prevent the occurrence opportunistic infections like TB.

The finding of this study in multivariate Cox modeling shows that nutritional status of children was not predictor of mortality. Even though this cohort reveals a high proportion child had either moderate or severe acute-malnutrition and malnutrition was a major contributor to deaths. Malnutrition impair immune reconstitution and there by prolong the period at which patient remain at increased risk of opportunistic infection. This is might be due to in this study 
nutritional status of children was assessed according to the guide line by considering weight and height as result malnutrition may represent over diagnosis related to recoding weight and height. This highlights the pressing need for improved diagnostics for malnutrition, it is better to use weight for age way of diagnosis.

Another covariate which was not predict mortality was advanced WHO clinical stage III and VI. As most studies, mortality was higher among children with advanced WHO clinical stage III and VI $[15,16,19]$, but in this study advanced WHO clinical stage III and VI was not predictor of mortality. This contrast might be associated with diagnostic procedure as well as skill of professional. Secondly it may associated with the type of care provide for children.

\section{Strength and Limitation of the Study}

Strengths of this study are the use of standard measurements which is enabled to make the comparison of findings with other national and international literatures to be valid. In addition, considering long duration of follow up period of children on ART which use of analytical study (retrospective cohort); the availability of data on important predictors of mortality (CPT, INH and Nutritional status). Since the outcome was death it was easy to establish temporal relationship with predictor variables which were documented at time of starting ART. Predictor variables were not biased by knowledge of the subjects' outcomes. It helps increase the quality of care given for children in ART clinic. It gives a clue how effective care and treatment of children on ART in resource limited settings like Ethiopia. It can serve as baseline information for further study, especially on the impact of INH and CPT prophylaxis of children on ART.

As limitation of this study mortality might be underestimated as the considerable number of children lost to follow up may include children who died. In addition, it is retrospective study and based on records availability of data for all variables were difficult and those with incomplete information were excluded from analysis, while missing data couldn't be ascertained and potential bias, we suspect that the impact should be minimal given that no more than $10 \%$ of values were missing for any given predictor (except in the case of viral load and HIV status of care giver) therefore, we excluded from analysis.

The sensitivity analysis was performed in order to determine the impact of lost to follow up by composite end point of LTFUP and death. According this study there was no significant difference, but mortality rate nearly double which is 5.52 per 1000 person month of observation. In bivarate analysis CD4 below threshold was not longer sig $(\mathrm{p}=0.542)$, but other variable remain significant and in multivariate analysis OI at baseline was not longer significant $(\mathrm{p}=0.237)$, but other variable remain significantly associated with death.

\section{Conclusions}

In this study a total of 65 deaths were reported in the follow-up period which gives an overall of 21175 person month of observation. The overall incidence rate mortality of cohort was 3.07 per 1000 person-months of observation and high mortality was observed in the first 6 months after initiation of treatment. The cumulative probability of survival at the end of $6^{\text {th }}, 12^{\text {th }}, 24^{\text {th }}, 60^{\text {th }}$ and $96^{\text {th }}$ month was $96.6 \%$, $95.9 \%, 93.4 \%, 82.9 \%$ and $73.9 \%$ respectively. The probability of survival of children on ART was $73.9 \%$ after 96 months and overall means survival time was 82.32 month. (95\% CI: 79.48-85.14). The main predictors of mortality among children after starting ART in our study area were Delayed/Regressed developmental milestone, Low
Hemoglobin level, Poor/Fair adherence to ART, OI at baseline, TB co infection at baseline, Absolute CD4 below threshold, Absence INH prophylaxis and cotrimoxazole prophylaxis. However, sex of children, Age of children, Advanced WHO clinical stage and nutritional status of children at baseline were not independent predictors of death.

\section{Acknowledgment}

We would like to sincerely thank health facilities administrator of both hospital and health facilities, health professionals, data collectors and friends who ever contributed for this work. We would also like to acknowledge Arba Minch University, College of Medicine and Health Sciences for finical support and facilitating the study.

\section{Authors' Contributions}

NB has made substantial intellectual contributions to conception, design, and acquisition of data, analysis and interpretation of data to this study. He also has been involved in drafting the manuscript and revising it critically for important intellectual contents. MK, BO and DM has made substantial contributions to conception, design, analysis and interpretation of data and participated in the critical review and editing of all the manuscript drafts for scientific merit and depth. All authors read and approved the final manuscript and agreed to be accountable for all aspects of the work in ensuring that questions related to the accuracy or integrity of any part of the work are appropriately investigated and resolved.

\section{References}

1. United Nations (2016) On the Fast Track to Ending the AIDS Epidemic: Report of the Secretary-General, United Nations, New York.

2. Panel on Antiretroviral Therapy and Medical Management of HIVInfected Children. Guidelines for the Use of Antiretroviral Agents in Pediatric HIV Infection. A Working Group of the Office of AIDS Research Advisory Council (OARAC). Addis Ababa: 2016.

3. World Health Organization. Consolidated guidelines on the use of antiretroviral drugs for treating and preventing HIV infection: recommendations for a public health approach 2013.

4. United Nations Children's Fund, For Every Child, End AIDS-Seventh stocktaking Report, UNICEF. New York 2016.

5. Ethiopian Health and Nutrition Research Institute. HIV/AIDS estimates and projections in Ethiopia, 2011-2016. Addis Ababa: 2012.

6. Ebissa G, Deyessa N, Biadgilign S (2016) Impact of highly active antiretroviral therapy on nutritional and immunologic status in HIVinfected children in the low-income country of Ethiopia. Nutrition 32.

7. Bitew S, Mekonen A, Assegid M (2016) Predictors on mortality of human immunodeficiency virus infected children after initiation of antiretroviral treatment in Wolaita zone health facilities, Ethiopia: Retrospective cohort study. J AIDS HIV Researc 9.

8. Collins IJ, Jourdain G, Hansudewechakul R, Kanjanavanit S, Hongsiriwon S, et al. (2010) Long-Term Survival of HIV-Infected Children Receiving Antiretroviral Therapy in Thailand: A 5-Year Observational Cohort Study. Clin Infect Dis 51: 1449-1457.

9. Kabue MM, Buck WC, Wanless SR, Cox CM, McCollum ED, et al. (2012) Mortality and Clinical Outcomes in HIV-Infected Children on Antiretroviral Therapy in Malawi, Lesotho,and Swaziland. Pediatrics 130: 591-599.

10. Federal HIV/AIDS. Prevention and Control Office [FHAPCO] (2016) Country Progress Report on the HIV Response, Federal Democratic Republic of Ethiopia. Addis Ababa.

11. Federal Democratic Republic of Ethiopia Ministry of Health [FMOH] (2014) National Comprehensive HIV Care and Treatment Training for Health Care Providers. Addis Ababa. 
Citation: Sidamo NB, Debere MK, Enderis B, Abyu DM (2017) Incidence and Predictors of Mortality among Children on Anti-Retroviral Therapy in Public Health Facilities of Arba Minch Town, Gamo Gofa Zone, Southern Ethiopia; Retrospective Cohort Study. Clinics Mother Child Health 14: 267. doi:10.4172/2090-7214.1000267

Page 11 of 11

12. Wamalwa DC, Obimbo EM, Farquhar C, Richardson BA, Mbori-Ngacha DA, et al. (2010) Predictors of mortality in HIV-1 infected children on antiretroviral therapy in Kenya: a prospective cohort. BMC Paediatr 10: 33.

13. Johannessen A, Naman E, Ngowi BJ, Sandvik L, Matee MI, et al. (2008) Predictors of mortality in HIV-infected patients starting antiretroviral therapy in a rural hospital in Tanzania. BMC Infect Dis 8: 52.

14. Zhao Y, Li C, Sun X, Mu W, McGoogan JM, et al. (2013) Mortality and treatment outcomes of China's National Pediatric antiretroviral therapy program. Clin Infect Dis 56: 3.

15. Ebonyi AO, Oguche S, Meloni ST, Sagay SA, Kyriacou DN, et al. (2014) Predictors of Mortality in a Clinic Cohort of HIV-1 Infected Children Initiated on Antiretroviral Therapy in Jos, Nigeria. J AIDS Clin Res 5: 403.

16. Ebissa G, Deyessa N, Biadgilign S (2015) Predictors of early mortality in a cohort of HIV-infected children receiving high active antiretroviral treatment in public hospitals in Ethiopia. AIDS care 27: 723-730.

17. Koye DN, Ayele TA, Zeleke BM (2012) Predictors of mortality among children on Antiretroviral Therapy at a referral hospital, Northwest Ethiopia: a retrospective follow up study. BMC Paediatr 12: 161.

18. Gebremedhin A, Gebremariam S, Haile F, Weldearegawi B, Decotelli C (2013) Predictors of mortality among HIV infected children on antiretroviral therapy in Mekelle Hospital, Northern Ethiopia: a retrospective cohort study. BMC Public Health 13: 1047.

19. Kedir AA, Desta A, Fesseha G (2014) Factors Affecting Survival of HIV Positive Children Taking Antiretroviral Therapy at Adama Referral Hospital and Medical College, Ethiopia. J AIDS Clin Res 5: 289.

20. Atnafu H, Wencheko E (2012) Factors affecting the survival of HIVinfected children after ART initiation in Bahir-Dar, Ethiopia. Ethiopian J Health Dev 26.
21. Moshago T, Haile DB, Enkusilasie F (2014) Survival Analysis of HIV Infected People on Antiretroviral Therapy at Mizan-Aman General Hospital, Southwest Ethiopia. Int J Sci Resear 3: 5.

22. Hosmer DW, Lemeshow S, S May (2008) Applied Survival Analysis: Regression Modeling of Time to Event Data: Second Edition, John Wiley and Sons Inc. New York.

23. Njom AE, Loussikila AB (2016) Predictors of mortality among HIVinfected children receiving highly active antiretroviral therapy. Med Mal Infect 47: 32-37.

24. Zanoni BC, Phungula T, Zanoni HM, France H, Feeney ME (2011) Risk factors associated with increased mortality among HIV infected children initiating antiretroviral therapy (ART) in South Africa. PloS one 6.

25. Taye B, Shiferaw S, Enquselassie F (2010) The impact of malnutrition in survival of HIV infected children after initiation of antiretroviral treatment (ART). Ethiop Med J 48: 1-10.

26. Mwiru RS, Spiegelman D, Duggan C, Seage GR, Semu H, et al. (2015) Nutritional Status and Other Baseline Predictors of Mortality among HIV-infected Children Initiating Antiretroviral Therapy in Tanzania. J Int Assoc Provid AIDS Care 14: 172-179.

27. Edessa D, Asefa F, Sheikahmed J (2015) Early Mortality among HIVpositive Children Initiated Anti-retroviral Therapy in Eastern Ethiopia: A Retrospective Cohort Study. Sci Tech Arts Resear J 4: 157-163.

28. Walker AS, Mulenga V, Ford D, Kabamba D, Sinyinza F, et al. (2010) The Impact of Daily Cotrimoxazole Prophylaxis and Antiretroviral Therapy on Mortality and Hospital Admissions in HIV-Infected Zambian Children. Clin Infect Dis 17: 1361-1367. 